\title{
A Novel Handoff Necessity Estimation Approach Based on Travelling Distance
}

\author{
Jyoti Madaan \\ Department of Electronics \& Communication Engineering, \\ Manav Rachna International University, Faridabad, 121003, India \\ E-mail: jyotiverma.fet@mriu.edu.in \\ Dr. Indu Kashyap \\ Department of Computer Science, \\ Manav Rachna International University, Faridabad, 121003, India \\ E-mail: indu.fet@mriu.edu.in
}

Received: 30 March 2017; Accepted: 08 June 2017; Published: 08 January 2018

\begin{abstract}
Mobility management is one of the most important challenges in Next Generation Wireless Networks (NGWNs) as it enables users to move across geographic boundaries of wireless networks. Nowadays, mobile communications has heterogeneous wireless networks offering variable coverage and Quality of Service (QoS). The availability of alternatives generates a problem of occurrence of unnecessary handoff that results in wastage of network resources. To avoid this, an efficient algorithm needs to be developed to minimize the unnecessary handoffs. Conventionally, whenever a Wireless Local Area Network (WLAN) connectivity is available, the mobile node switch from the cellular network to wireless local area network to gain maximum use of high bandwidth and low cost of wireless local area network as much as possible. But to maintain call quality and minimum number of call failure, a considerable proportion of these handovers should be determined. Our algorithm makes the handoff to wireless local area network only when the Predicted Received Signal Strength (PRSS) falls below a threshold value and travelling distance inside the wireless local area networkis larger than a threshold distance. Through MATLAB simulation, we show that our algorithm minimizes the probability of unnecessary handoff, and probability of handoff failure. Hence, the proposed algorithm is able to improve handover performance.
\end{abstract}

Index Terms-Predicted Received Signal Strength (PRSS), Wireless Local Area Network (WLAN), Vertical Handoff Decision (VHD), Quality of Service (QoS), Point of Attachment (PoA).

\section{INTRODUCTION}

Heterogeneous wireless networks are one of the most important structures that are needed for deployment of wireless technologies such as $4 \mathrm{G}$ mobile systems. The heterogeneous network is the group of technologies which can be accessed to allow the user to have seamless mobility and best quality of service at all time such as high coverage of cellular networks and high bandwidth of Wireless Local Area Network (WLAN) [1]. To allow seamless mobility and always best connected services to mobile user, there is a need to develop an efficient Vertical Handoff Decision (VHD) algorithm. Mobility management comprises of Location management and Handover management. The information delivery is being tracked with the help of Location management and discovers its current Point of Attachment (PoA). Although, the Handover management maintains a mobile node's active connection while moving from one PoA to another [2]. Handover is defined as the process in which the channel frequency, time slot, spreading code or may be combination any of them is being changed while the current call is in progress. Handoff is divided into two categories as horizontal and vertical handoff on the basis of the kind of network under use [3]. There is a one more kind of handover, known as group handover was produced at the time trains, buses or other vehicles are on the way. The group handovers or cooperative handovers are used to balance the load through the utilization of cooperative communication [4].

\section{RELATED WORK}

Lots of work has been done by researchers on the VHD process to minimize the handoff failures and unnecessary handoff. Few of them are listed as follows.

In an existing travelling distance prediction handoff algorithm proposed by Yan et. al, the handoff occurs when the predicted travelling distance is greater than the distance threshold [5]. This algorithm provides constant values of probability of handover failure and unnecessary handover. The constant value of probability of handover failure and unnecessary handover is very high for low velocity user.

After that an enhanced VHD model based on Predicted Received Signal Strength (PRSS) and dwell time value is proposed by Kunarak and Suleesathira (2013). The 
received signal strength is predicted by a backpropagation neural network to initiate a handoff early. The value of dwell time depends upon the mobile node velocity and moving pattern. They have designed multiple metric based policies for real time and non real time services in different networks. They have designed handoff triggering process to check the consistency of RSS during a whole dwell time duration for triggering handoff process. So that unnecessary handoff can be avoided. In future, the algorithm can be utilized for calculating handoff delay and throughput for real time services [6].

Bo et al., in 2014 have proposed a multi-attribute vertical handoff algorithm based on node mobility. The current access point pre-switch to the adjacent access points, and the handoff is triggered when the signal coverage rate of the access point is below a preset threshold. Detailed simulation results show the performance improvement in a proposed algorithm as compared to traditional multi-attribute decision making algorithm [7].

Later on, in 2015 Gao and Zhang have proposed a mechanism to select best access network for Low Power Mobile Terminal (LPMT) in integrated WLAN/UMTS environment. The adaptive weights are used to reduce unnecessary handoff and to extend battery lifetimes of low power mobile terminal without impacting the perceived quality of service (QoS) [8].

Also, there are some cases in which conventional distance predicted handoff algorithm cannot provide an effective handover decision. Following are the two cases in which handover to a mobile node cannot be provided through a conventional algorithm when it is actually required.

\section{Case 1}

The cellular network and WLAN overlap with each other as shown in Fig. 1(a) Let us assume, the mobile node enters from the cellular network (point $\mathrm{P}_{\mathrm{i}}$ ) into the WLAN and will exit from another point $\mathrm{P}_{\mathrm{o}}$. Now, as mobile node travels in the WLAN, it covers some distance. Therefore, conventional approaches provide the handover to the mobile node on the basis of travelled distance in this situation. But, the strength of the cellular network as well as WLAN is sufficiently strong to provide service continuity in this trajectory. Therefore, handoff is actually not required in this situation.

\section{Case 2}

In the second scenario as shown in Fig. 1 (b), the mobile node enters from the cellular network (point $\mathrm{P}_{\mathrm{i}}$ ) into the WLAN and will exit from another point $\mathrm{P} o$. According to conventional approaches, the shortest travelled distance (d) is very small as compared to threshold distance. Therefore, handoff cannot be provided to the mobile node through conventional approach, but it is actually needed as mobile node has travelled a sufficient distance in a WLAN.

To overcome the above said issues we need to optimize the handoff algorithm to handle such type of situations. So, in presenting algorithm handoff is done on the basis of travelling distance with respect to radius $\left(\mathrm{R}_{\mathrm{d}}\right)$ instead of travelling distance (d).

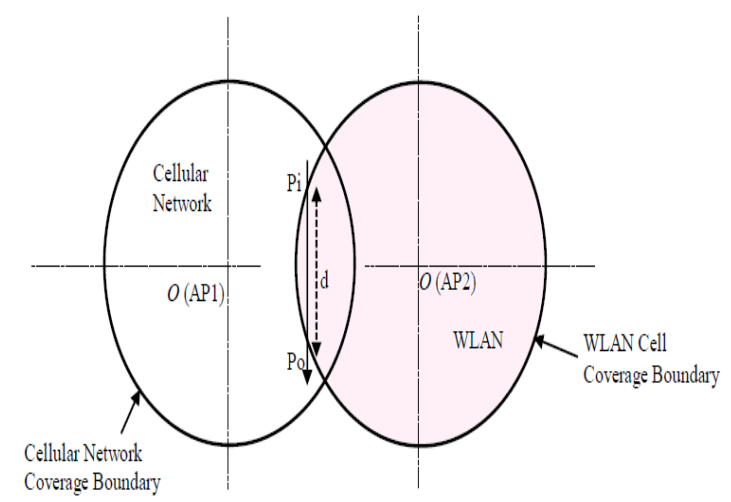

Fig.1. (a). Overlapping Structure of Cellular Network and WLAN

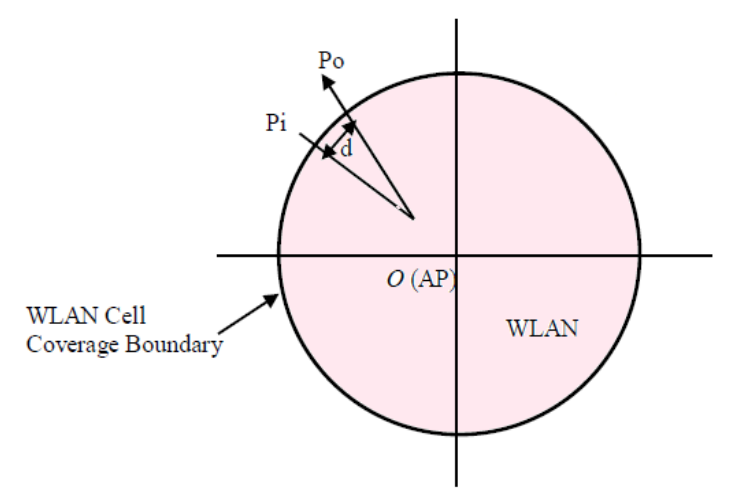

Fig.1. (b). Shortest Predicted Distance

In an overlapped architecture as shown in Fig. 2 (a), estimated travelling distance with respect to radius $\left(R_{d}\right)$ is smaller than the threshold distance $\left(R_{d_{\text {travelled }}} \geq\right.$ dis $\left.\tan c e_{\text {threshold }}\right)$. Therefore, handoff is not provided through presented algorithm. Which is actually not required. Although the conventional method provides handoff in this case.

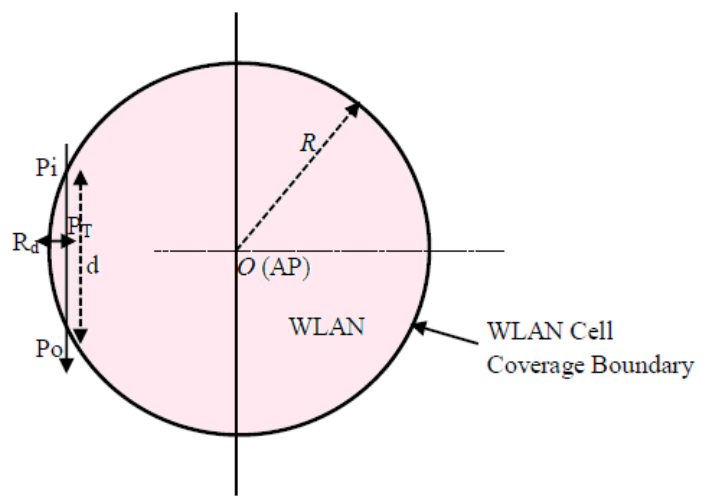

Fig.2. (a). Travelling Distance w.r.t. to Radius $\left(R_{d}\right)$ in Overlapping Structure

In shortest predicted distance architecture as shown in Fig. 2 (b), estimated travelling distance with respect to radius $\left(R_{d}\right)$ is larger than the threshold distance ( $R_{d_{\text {travelled }}} \geq$ dis $\left.\tan c e_{\text {threshold }}\right)$. Therefore, handoff is 
provided through presented algorithm, although the conventional method can't provide handoff in this case.

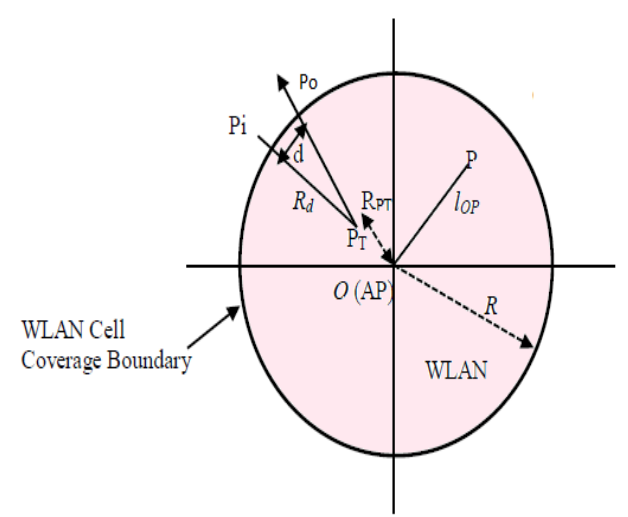

Fig.2. (b). Travelling Distance w.r.t to Radius $\left(\mathrm{R}_{\mathrm{d}}\right)$ in Shortest Predicted Distance Structure

The presented algorithm improves the handover performance by estimating the necessity of making handoff. The next section explains the Handoff Necessity
Estimation Module, Received Signal Strength Prediction and estimation of travelling distance with respect to radius.

\section{OVERVIEW OF HANDOFF NECESSITY ESTIMATION MODUlE (HNEM)}

The Handoff Necessity Estimation Module (HNEM) determines the necessity of making a handover to an available network. HNEM module includes three algorithms- received signal strength prediction, travelling distance estimation with respect to radius, and candidate network selection algorithm. It takes predicted received signal strength (PRSS) of current serviced network, neighbor network, threshold RSS of serviced network and travelling distance of the mobile node as inputs, generating the requirement of making the handoff as its output. It also selects the candidate networks from the available networks. The block diagram of HNEM is shown in Fig. 3.

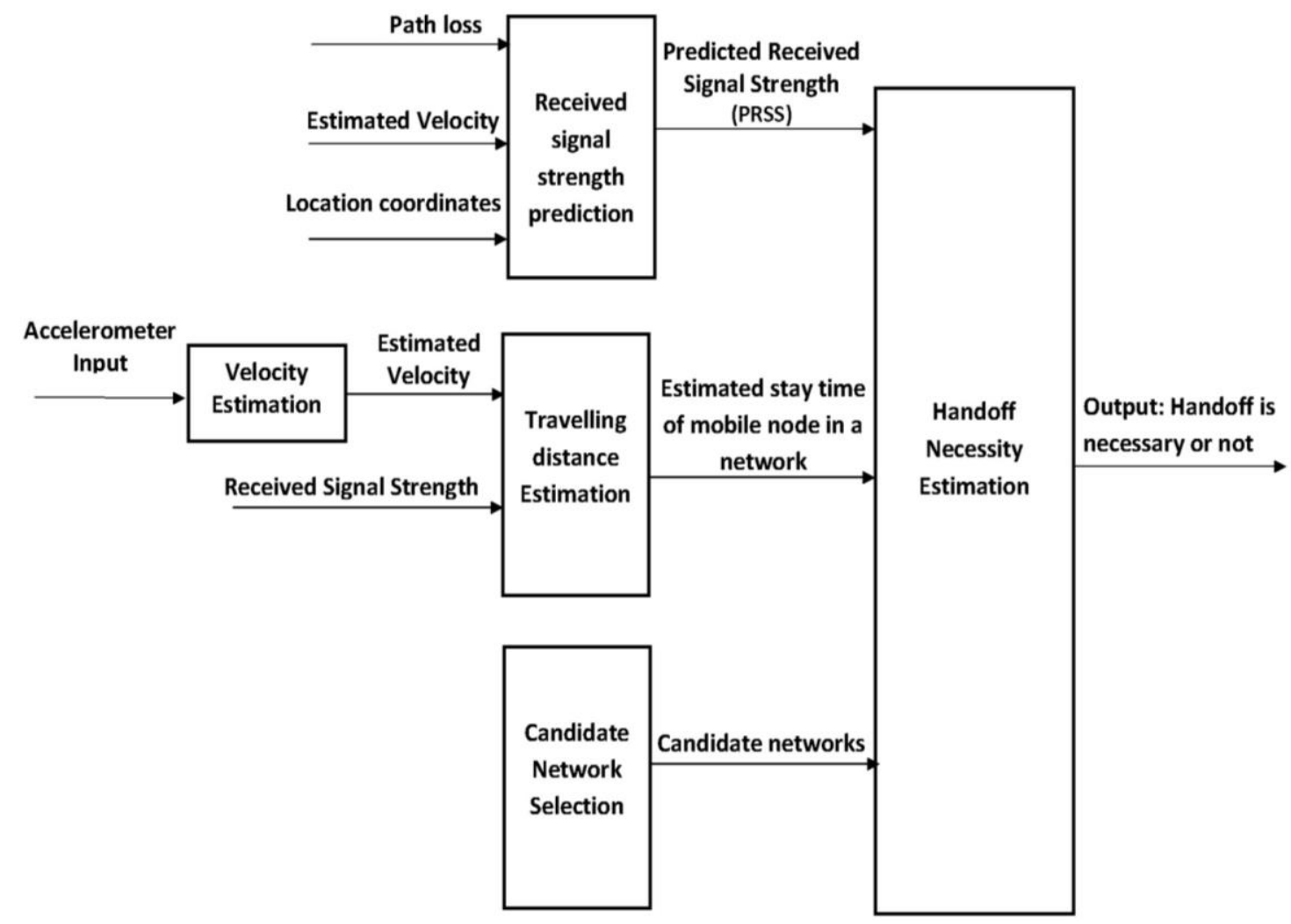

Predicted Received

Signal Strength

Fig.3. Handoff Necessity Estimation Module (HNEM)

The output of HNEM is one to indicate that the PRSS of current serviced network is not enough to provide services to the mobile node as well as estimated travelling distance or stay time of the mobile node in a network is very high as compared to threshold distance and is therefore a handoff is required. Otherwise, output is 0 i.e. handoff is not required.

$$
\mathrm{HNEM}=\left\{\begin{array}{l}
\mathrm{PRSS}_{\mathrm{ser}}<\mathrm{RSS}_{\mathrm{th}} \& \mathrm{R}_{\mathrm{d}} \geq \mathrm{d}_{\mathrm{th}}=1, \\
0
\end{array}\right\}
$$

The estimation of handoff necessity relies on the accuracy of Received Signal Strength (RSS) measurement. The next section shows the input parameters estimation of HNEM. 


\section{A. Received Signal Strength Prediction Using Levenberg Marquardt Algorithm}

The estimation of the handover necessity is based on an algorithm attempting for the prediction of the RSS by using successive RSS measurements. Received Signal Strength is a measure of quality of signal perceived by the mobile node. The Received Signal Strength and the mobile node movement are directly proportional to each other. Which helps in estimating that whether the mobile node is moving away or closer to the monitored network.

In recent years, Artificial Neural Network (ANNs) has proven as the successful algorithm for the purpose of prediction of RSS in rural, suburban, and in an indoor environment as well [9]. An artificial neural network is developed based on the human brain, which are complex, nonlinear, and capable of working in parallel or in a distributed environment and also can perform the local processing and adoption of the information as well.

The field strength prediction is done between two points and can also be considered as a function with several inputs and a single output [10] [11]. The inputs contain information about the mobile node speed, path loss, distance, etc. while the output gives the RSS for those inputs.

The presented approach use multilayer perception (MLP) for propagation simulation that is shown in the Fig. 4 with four layers: the input layer, two hidden layers and an output layer. The neuron network is completely interconnected. This means that feed forward processing of the ANN is possible. Three different types of signals are being identified in this network:

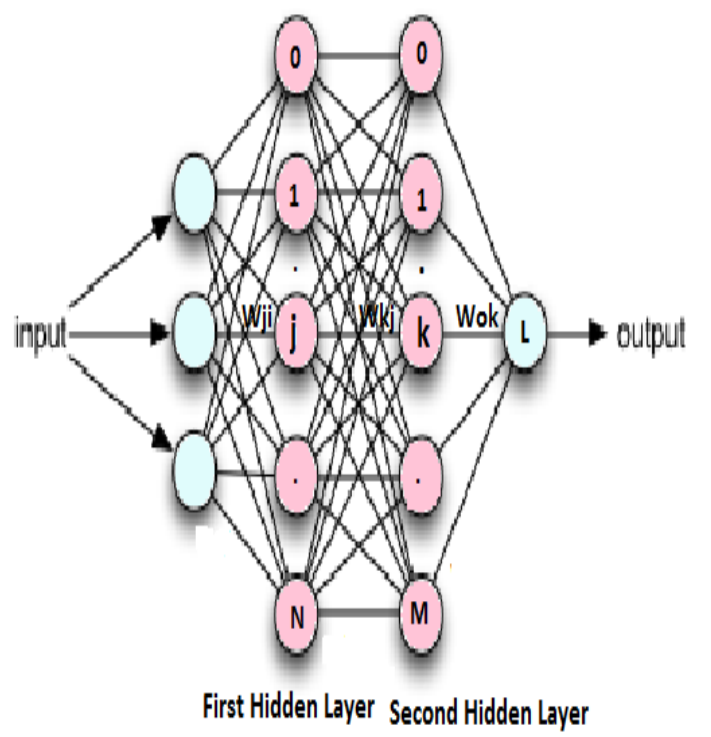

Fig.4. Feed Forward Multilayer Perception (MLP)

- The input signal is presented at the input layer of the network and propagates in a forward direction to reach the other end of the network as output signal. Each input unit receives the input signal (path loss, velocity, and location coordinates of the mobile node) and transmits this signal to all hidden layers. The output signal is being computed by applying the addition of the weights of the input signal for each hidden unit in the activation function.

- As the ANN is the back propagation algorithm, hence the error signals that are generated at the output layer propagates backwards from the output layer to hidden layer and so on in the ANN network. This is a defined function for the target and the actual output.

- The output of the neural network represents the signal strength. Synaptic weights are used to connect the inputs to the first hidden layer of the network. As the network uses the forward processing hence the output of the first hidden layer is the input to the second hidden layer, and all its neurons are connected to the output layer of the network.

Below mathematical equation describes the output of the network:

$$
\mathrm{P}_{\mathrm{r}}=\phi_{\mathrm{O}} \sum_{\mathrm{k}=1}^{\mathrm{L}} \mathrm{w}_{\mathrm{Ok}}\left(\phi_{\mathrm{h} 2}\left(\sum_{\mathrm{j}=1}^{\mathrm{M}} \mathrm{w}_{\mathrm{kj}} \mathrm{v}_{\mathrm{j}}\left(\phi_{\mathrm{h} 1}\left(\sum_{\mathrm{i}=1}^{\mathrm{N}} \mathrm{w}_{\mathrm{ji}} \mathrm{u}_{\mathrm{i}}\right)\right)\right)\right)
$$

where N, M, L depicts the total number of neurons in the first hidden layer, second hidden layer, and output layer respectively. $\mathrm{W}_{\mathrm{Ok}}$ is synaptic weights from neuron $\mathrm{k}$ in the second hidden layer to the single output neuron, $V_{j}$ is $\mathrm{j}^{\text {th }}$ element of the vector that inputs to the second hidden layer, $\mathrm{W}_{\mathrm{kj}}$ is connection weights between neurons in the two hidden layers, $U_{i}$ is $i^{\text {th }}$ element of the vector that inputs to the first hidden layer, $\mathrm{W}_{\mathrm{ji}}$ is connection weights between inputs and the first hidden layer, $\phi_{\mathrm{h} 1}, \phi_{\mathrm{h} 2}$ and $\phi_{0}$ are activation functions in the first, second and output layers respectively.

The activation function of the output layer is a linear function, while the activation function of the hidden layers is sigmoid type. It can be given by the equation

$$
\phi(\mathrm{a}, \mathrm{v})=\frac{1-\mathrm{e}^{-\mathrm{av}}}{1+\mathrm{e}^{-\mathrm{av}}}
$$

where a depicts the activation function's slope. Activation function is used to evaluate the duration of the network training, so that the training speed can be adjusted by changing the available parameters. In the neural network, it's not possible to define the slope of the activation function for every neuron, so their estimation is made in an adaptive way during the process of training.

The following assumptions are made for the step by step execution of the algorithm:

- There exists the circular geometry in the WLAN.

- The mobile node moves in a straight line with constant speed in the WLAN.

- The propagation environment is modeled using the path loss model. 
The signal strength received by the mobile node in a WLAN at distance $\mathrm{x}$ can be calculated as [12]

$$
\operatorname{RSS}(x)=10 \log \left(\frac{100}{(39.37 x)^{\gamma}}\right)
$$

Similarly, received signal strength for UMTS at distance $\mathrm{x}$ can be calculated as [13].

$$
\begin{aligned}
& \mathrm{PL}(\mathrm{x})=\mathrm{Z}+10 \beta \log (\mathrm{x})+\chi_{\sigma} \\
& \operatorname{RSS}(\mathrm{x})=\mathrm{P}_{\mathrm{tx}}-\mathrm{PL}(\mathrm{x})
\end{aligned}
$$

where $\gamma$ is an environmental factor, $\operatorname{RSS}(\mathrm{x})$ is received signal strength at distance $\mathrm{x}, \mathrm{P}_{\mathrm{tx}}$ is transmitted power $(1 \mathrm{~W})$, and $\mathrm{PL}(\mathrm{x})$ is path loss at a distance $\mathrm{x}$ between mobile node and base station, $\mathrm{Z}$ is path loss constant, $\beta$ is path loss exponent.

\section{B. Travelling Distance Estimation with respect to Radius}

The travelling distance in a WLAN with respect to radius is predicted by using continuous RSS measurement. Let us assume the mobile node enters in WLAN at point $\mathrm{P}_{\mathrm{i}}$ and will exit the WLAN from point $\mathrm{P}_{\mathrm{o}}$, and current position of mobile node in WLAN network is $\mathrm{P}_{\mathrm{T}}$ as shown in Fig. 5.

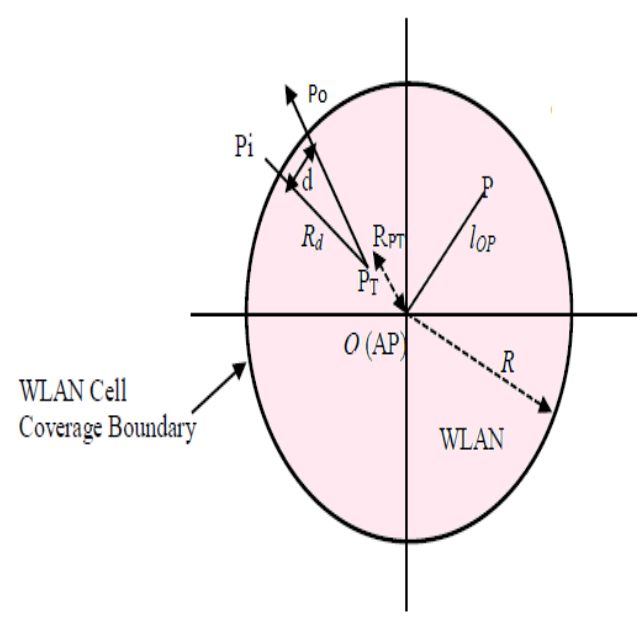

Fig.5. Estimated Travelling Distance at Point $\mathrm{P}_{\mathrm{T}}$

The Lognormal path loss model is used to represent the relation in RSS (in $\mathrm{dBm}$ ), and distance from mobile node to access point (AP) at any point $\mathrm{P}$ in the available network [14] [15].

$$
R S S_{P}=P_{t X}-10 \beta \log _{10} I_{O P}+\chi_{\sigma}
$$

Equation (7) is used to calculate the relationship between the distance $l_{\mathrm{OPi}}$ and cell radius inside the WLAN

$$
R=P_{t X}-I_{O P i}=10 \frac{P_{t X}-R S S_{P i}}{10 \beta}
$$

Similarly radius at point $\mathrm{P}_{\mathrm{T}}$ is given by

$$
R_{P_{T}}=P_{t X}-I_{O P_{T}}=10 \frac{P_{t X}-R S S_{P_{T}}}{10 \beta}
$$

So, mobile node's travelling distance w.r.t radius $\left(\mathrm{R}_{\mathrm{d}}\right)$ can be calculated as:

$$
\text { Travelling distance }\left(R_{d}\right)=R-R_{P_{T}}
$$

Suppose $\mathrm{V}$ is the velocity of mobile node and $\mathrm{T}$ is the time taken by the mobile node to reach point $\mathrm{P}_{\mathrm{T}}$, then the actual distance travelled (d) by the mobile node in a WLAN to reach $\mathrm{P}_{\mathrm{T}}$ is

$$
\text { Actual distance travelled }(d)=V T
$$

where $\mathrm{P}_{\mathrm{tx}}$ is the transmition power of the AP $(\sim 20 \mathrm{dBm})$, $\beta$ is the path loss exponent (ranges inbetween 2 and 5), $\chi_{\sigma}$ is a Gaussian distributed random variable with a zero mean and standard deviation $\left(\begin{array}{llll}\sigma & \sim 12 & \mathrm{~dB}\end{array}\right), \mathrm{RSS}_{\mathrm{Pi}}$ represents received signal strength at entry point, $\mathrm{RSS}_{\mathrm{PT}}$ is received signal strength at mobile node current position $\mathrm{P}_{T}, \mathrm{R}$ is radius of WLAN, $\mathrm{R}_{\mathrm{PT}}$ is radius at point $\mathrm{P}_{T}, \mathrm{P}_{\mathrm{T}}$ is current location of mobile node in WLAN, $1_{\mathrm{OP}}$ is the distance between point $\mathrm{P}$ and the AP, $1_{\mathrm{Opi}}$ is distance between entry point $\mathrm{P}_{\mathrm{i}}$ and the $\mathrm{AP}$, and $\mathrm{l}_{\mathrm{OPT}}$ is distance between current location $\mathrm{P}_{\mathrm{T}}$ and the AP.

Note: Actual distance travelled by mobile node in WLAN may be greater than $\mathrm{R}_{\mathrm{d}}\left((d)=V T \geq R_{d}\right)$. If the mobile node moves different from the straight line, like in zigzag pattern.

\section{Candidate Network Selection}

The candidate networks are discovered from the available networks. A candidate network is defined as the network which can support the services requested by the mobile user. A Minimum Guarantee Function (MGF) is computed so as to select the candidate network, and the MGF is defined as the function which denotes whether the network supports the minimum requirement of the mobile node or not. It is a function of received signal strength, bandwidth, power requirement, service cost, and velocity of the mobile node [16].

The Minimum Guarantee Function of a network 1 is given by:

$$
\begin{aligned}
& \mathrm{MGF}_{1}=\mathrm{f}\left(\mathrm{PRSS}_{1}-\mathrm{RSS}_{\mathrm{th}}\right) * \mathrm{f}\left(\mathrm{BW}_{1}-\mathrm{BW}_{\mathrm{th}}\right) * \\
& \mathrm{f}\left(\mathrm{PO}_{1}-\mathrm{PO}_{\mathrm{th}}\right) * \mathrm{f}\left(\mathrm{CO}_{1}-\mathrm{CO}_{\mathrm{th}}\right) * \mathrm{f}\left(\mathrm{V}_{\mathrm{mn}_{1}}-\mathrm{V}_{\mathrm{th}}\right)
\end{aligned}
$$

where $\mathrm{PRSS}_{\mathrm{l}}, \mathrm{BW}_{\mathrm{l}}, \mathrm{PO}_{\mathrm{l}}, \mathrm{CO}_{\mathrm{l}}, \mathrm{V}_{\mathrm{mn}}$, represents predicted received signal strength, bandwidth, power consumption, service cost, and velocity of a mobile node in a network 1 . $\mathrm{RSS}_{\mathrm{th}}, \mathrm{BW}_{\mathrm{th}}, \mathrm{PO}_{\mathrm{th}}, \mathrm{CO}_{\mathrm{th}}, \mathrm{V}_{\text {th }}$ are the predefined thresholds of received signal strength, bandwidth, power requirement, service cost, and supported mobile node's velocity of a particular network 1 . 
The minimum guarantee function is defined as the unit step function, whose value is defined as 0 or 1 on the basis of the argument whether the argument is negative or positive. Therefore, it can be represented as a unit step function [17]. If the value of any parameter is lower than the threshold, then the value of the MGF is set to zero. As the result of that, the current network is not considered as candidate network anymore. Else the current network is added to the candidate network.

By introducing the mobile node velocity into the minimum guarantee function, elimination of the pingpong effect can be done efficiently. For example, if mobile node's speed is over the supported speed, then the WLAN will not support the same. Handover to WLAN in that situation will not work. For certain users the battery power is crucial. For example, if the battery power is low, then the mobile node can switch to the network, which has a less power requirement as Adhoc and Bluetooth network. Switching to a network that require higher power requirement will not be beneficial in this.

Since equation (12) is quite simple and the estimation of the parameters can be done easily, hence the time consumption is very low in the case of the pre-handoff decision.

\section{RESEARCH METHODOLOGY}

Fig. 6 shows algorithm for the handover necessity estimation. The mathematical arguments used to estimate the necessity of making handoff are presented below. A handover is required, if one of the two conditions is satisfied:

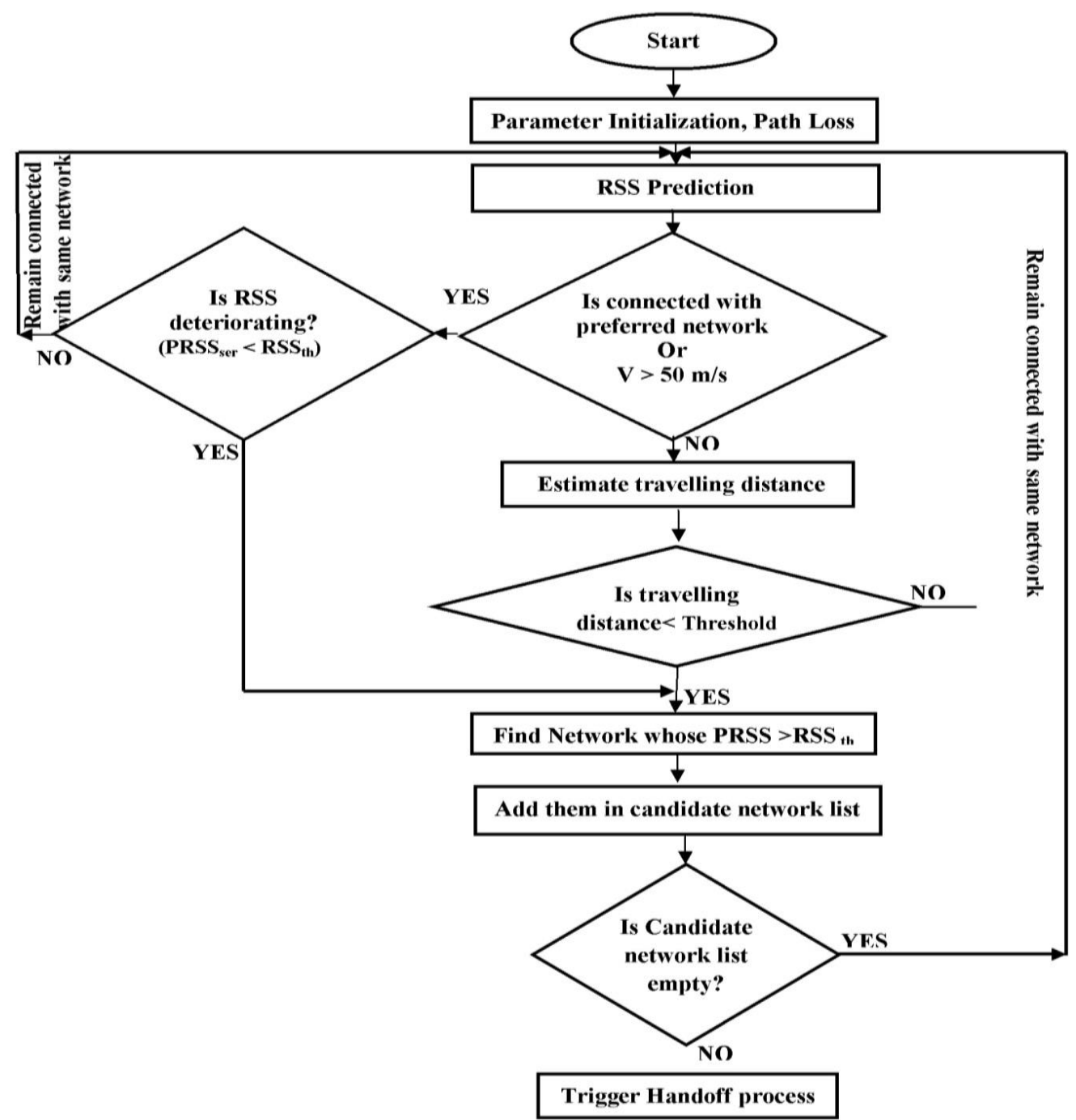

Fig.6. Flowchart of Handoff Necessity Estimation Algorithm

i. The mobile node is travelling away from the current network and received signal strength from mobile node starts continuously deteriorating. In other words the PRSS from the current serviced network falls below the RSS threshold of current network $\left(\mathrm{PRSS}_{\mathrm{ser}} \leq \mathrm{RSS}_{\mathrm{th}, \mathrm{ser}}\right.$ ) and the RSS from the neighbor networks starts increasing, which means the mobile node is near the boundary area.

ii. The travelling distance of the mobile node is greater than the threshold travelled distance. Threshold travelled distance refers to a minimum distance travelled by mobile node in a network for initiating a handoff. 
Above two equations, estimates the necessity of making the handoff in order to minimize the handoff failure and unnecessary handoff. In the case that above two conditions fail, it means the mobile node is not moving out of the coverage area; there is no need to handoff.

Handover necessity estimation algorithm minimizes the probability of handoff failure and unnecessary handoff, which can be calculated as follows.

\section{A. Probability of Unnecessary Handoff}

It refers to a frequent handovers between access networks. If the estimation of the necessity of making the handoff goes wrong, then the handoff algorithm will be too fast or too slow, by which the resources of the network are wasted or can result in unnecessary handoff. Hence so as to properly use the network resources the handoff estimation should be done properly.

An unnecessary handoff occurs if the travelling time inside the WLAN is shorter than the sum of the handover time into $\left(\tau_{\mathrm{i}}\right)$ and out of $\left(\tau_{\mathrm{o}}\right)$ the WLAN.

The probability of unnecessary handoff for existing travelling distance algorithm proposed by Yan et al. in 2008 [5], Hysteresis based method (TDE) proposed by Liu et al. in 2008[19] and presented algorithm (PTD) can be calculated as:

$$
P_{\text {Uhtran }}=\frac{2}{\pi}\left[\begin{array}{l}
\sin ^{-1}\left(\frac{V\left(\tau_{i}+\tau_{O}\right)}{2 R}\right)-\sin ^{-1}\left(\frac{T_{\text {th }}}{2 R}\right), 0 \leq T_{\text {th }} \leq\left(\tau_{i}+\tau_{O}\right) \\
0,\left(\tau_{i}+\tau_{O}\right)<T_{\text {th }}
\end{array}\right]
$$

$$
\mathrm{P}_{\mathrm{Uhf}_{\mathrm{TDE}_{\mathrm{hys}}}}=\left\{\begin{array}{l}
1, \mathrm{v}\left(\mathrm{t}_{\mathrm{dC}}+\mathrm{t}_{\mathrm{dW}}\right)>2 \mathrm{~d}_{\mathrm{hys}} \\
\frac{2}{\pi} \sin ^{-1}\left(\frac{\mathrm{V}\left(\mathrm{t}_{\mathrm{dC}}+\mathrm{t}_{\mathrm{dW}}\right)}{2 \mathrm{~d}_{\text {hys }}}\right), 0 \leq \mathrm{V}\left(\mathrm{t}_{\mathrm{dC}}+\mathrm{t}_{\mathrm{dW}}\right) \leq 2 \mathrm{~d}_{\mathrm{hys}}
\end{array}\right\}
$$

$$
\mathrm{P}_{\text {Uhf }_{\mathrm{PTD}(\text { PRSS }} \text { trancelingatis+Dwell }}=\left\{\begin{array}{l}
1, \mathrm{~V}\left(\tau_{\mathrm{i}}+\tau_{\mathrm{O}}\right)>2 \mathrm{R}_{\mathrm{d}} \\
\frac{2}{\pi} \sin ^{-1}\left(\frac{\mathrm{v}\left(\tau_{\mathrm{i}}+\tau_{\mathrm{O}}\right)}{2 \mathrm{R}_{\mathrm{d}}}\right), 0 \leq \mathrm{V}\left(\tau_{\mathrm{i}}+\tau_{\mathrm{O}}\right) \leq 2 \mathrm{R}_{\mathrm{d}}
\end{array}\right\}
$$

where $R_{d}$ is estimated travelling distance with respect to radius, $\mathrm{R}$ is radius of WLAN, $\mathrm{T}_{\text {th }}$ is threshold handoff latency time; which is selected by system designer [5] [18], $d_{\text {hys }}$ is distance between the mobile node and WLAN access point when handoff occurs in hysteresis based algorithm, $t_{d W}$ is handover delay from cellular network to WLAN, $t_{d C}$ is handover delay from cellular network to WLAN.

\section{B. Probability of Handover Failure}

A handoff failure occurs when a travelling distance inside the WLAN is shorter than the threshold distance ( $R_{d_{\text {traveling }}} \leq d_{\text {threshold }}$ ). A threshold distance is a product of mobile node velocity and handover latency.
The Probability of handover failure of the existing travelling distance algorithm [5], Hysteresis based method (TDE) [19] and presented algorithm (PTD) can be calculated as:

$$
\begin{aligned}
& P_{h f_{T D E Y a n}}=\left\{\begin{array}{l}
\frac{2}{\pi}\left[\sin ^{-1}\left(\frac{V \tau_{i}}{2 R}\right)-\sin ^{-1}\left(\frac{V T_{t h}}{2 R}\right)\right], 0 \leq T_{t h} \leq \tau_{i} \\
0, \tau_{i}<T_{t h}
\end{array}\right\} \\
& \mathrm{P}_{\mathrm{hf}_{\mathrm{TDE}_{\mathrm{hys}}}}=\left\{\begin{array}{l}
1, \mathrm{Vt}_{\mathrm{dc}}>2 \mathrm{~d}_{\mathrm{hys}} \\
\frac{2}{\pi} \sin ^{-1}\left(\frac{\mathrm{Vt}_{\mathrm{dc}}}{2 \mathrm{~d}_{\mathrm{hys}}}\right), 0 \leq \mathrm{Vt}_{\mathrm{dc}} \leq 2 \mathrm{~d}_{\mathrm{hys}}
\end{array}\right\} \\
& \mathrm{P}_{\left.\mathrm{hf}_{\text {PTD }} \text { (PRSS }+ \text { traveling+Dwell }\right)}=\left\{\begin{array}{l}
1, \mathrm{~V} \tau_{\mathrm{i}}>2 \mathrm{R}_{\mathrm{d}} \\
\frac{2}{\pi} \sin ^{-1}\left(\frac{\mathrm{V} \tau_{\mathrm{i}}}{2 \mathrm{R}_{\mathrm{d}}}\right), 0 \leq \mathrm{V} \tau_{\mathrm{i}} \leq 2 \mathrm{R}_{\mathrm{d}}
\end{array}\right\} \\
& \mathrm{d}_{\mathrm{hys}}=10 \frac{\mathrm{P}_{\mathrm{tx}}-\mathrm{RSS}_{\text {hys }}}{10 \beta}
\end{aligned}
$$

where $\tau_{i}$ is handover time into WLAN, $\mathrm{R}$ is radius of WLAN, $V$ is velocity of mobile nodes, $t_{d c}$ is handover delay from the cellular network to WLAN network, $t_{d W}$ is handover delay from cellular network to WLAN network, $d_{\text {hys }}$ represents the distance between the mobile node and WLAN access point when handoff occurs in the Hysteresis based method, $\mathrm{P}_{\mathrm{tx}}$ is transmitted power.

\section{SiMULATION SETUP}

MATLAB 7.12.0.635 (R2011a) is used as the simulation tool for the performance evaluation of the proposed algorithm. In the simulation an overlaid architecture of single cellular network (UMTS), fourteen WLAN and three Wi-MAX are considered to cover an area of $3000 * 3000 \mathrm{~m}$ as shown in Fig. 7. The

Table 1. Network Parameters

\begin{tabular}{|c|c|c|}
\hline Parameters & Symbol & Value \\
\hline Path loss exponent & $\beta$ & 3.5 \\
\hline Path loss constant & $\mathrm{Z}$ & $19 \mathrm{dBm}$ \\
\hline $\begin{array}{c}\text { Shadow effect (Gaussian random } \\
\text { variable with zero mean and standard } \\
\text { deviation) }\end{array}$ & $\chi_{\sigma}$ & $6-12(\mathrm{~dB})$ \\
\hline $\begin{array}{c}\text { Environment factors } \\
\text { to reach point } \mathrm{P}_{\mathrm{T}}\end{array}$ & $\gamma$ & 2.8 \\
\hline $\begin{array}{c}\text { T is the time taken by the mobile node } \\
\text { Threshold travelled distance in WLAN }\end{array}$ & $\mathrm{d}_{\mathrm{th}}$ & $2.20 \mathrm{sec}$ \\
\hline $\begin{array}{c}\text { Travelling time to move into the } \\
\text { WLAN }\end{array}$ & $\tau_{\mathrm{i}}$ & 2 \\
\hline $\begin{array}{c}\text { Travelling time to move out from the } \\
\text { WLAN }\end{array}$ & $\tau_{\mathrm{O}}$ & 2 \\
\hline $\begin{array}{c}\text { Distance between the mobile node and } \\
\text { WLAN access point when handoff } \\
\text { occurs }\end{array}$ & $\mathrm{d}_{\mathrm{hys}}$ & 120 \\
\hline \begin{tabular}{c} 
The \\
\hline
\end{tabular} & & \\
\hline
\end{tabular}


transmission range of UMTS covers an area of $3000 \mathrm{~m}$, Wi-MAX covers an area of $1000 \mathrm{~m}$ and WLAN covers an area of $250 \mathrm{~m}$. The bandwidth of UMTS, WLAN and WiMAX are $384 \mathrm{~kb} / \mathrm{s}, 11 \mathrm{Mb} / \mathrm{s}$, and $15 \mathrm{Mb} / \mathrm{s}$, respectively. Thousands of random trajectories of the mobile node from UMTS to WLAN are generated. For each trajectory, a random entry and exit point in WLAN cell is considered. Table 1 and 2 defines the various network parameters and simulation parameters considered for the simulation.

Table 2. Simulation Parameters

\begin{tabular}{|c|c|c|}
\hline Network parameters & WLAN & UMTS \\
\hline $\begin{array}{c}\text { RSS of downward } \\
\text { Min/max/th }(\mathrm{dBm})\end{array}$ & $-80 /-70 /-92$ & $-/-/-115$ \\
\hline $\begin{array}{c}\text { RSS of upward } \\
\text { Min/max/th }(\mathrm{dBm})\end{array}$ & $-95 /-92 /-94$ & $-/-/-115$ \\
\hline $\begin{array}{c}\text { Bandwidth (Mbps) } \\
\text { Min/max/th }\end{array}$ & $1 / 4 / 1$ & $0.1 / 0.384 / 0.1$ \\
\hline $\begin{array}{c}\text { Cost } \\
\text { Min/max/th }\end{array}$ & $0.1 / 0.4 / 0.1$ & $0.7 / 2.5 / 0.7$ \\
\hline $\begin{array}{c}\text { Transmission power }\left(\mathrm{P}_{\mathrm{tx}}\right) \\
(\mathrm{W})\end{array}$ & 0.1 & 1.0 \\
\hline $\begin{array}{c}\text { Mobile node velocity } \\
(\mathrm{m} / \mathrm{s})\end{array}$ & $<3$ & $<80$ \\
\hline
\end{tabular}

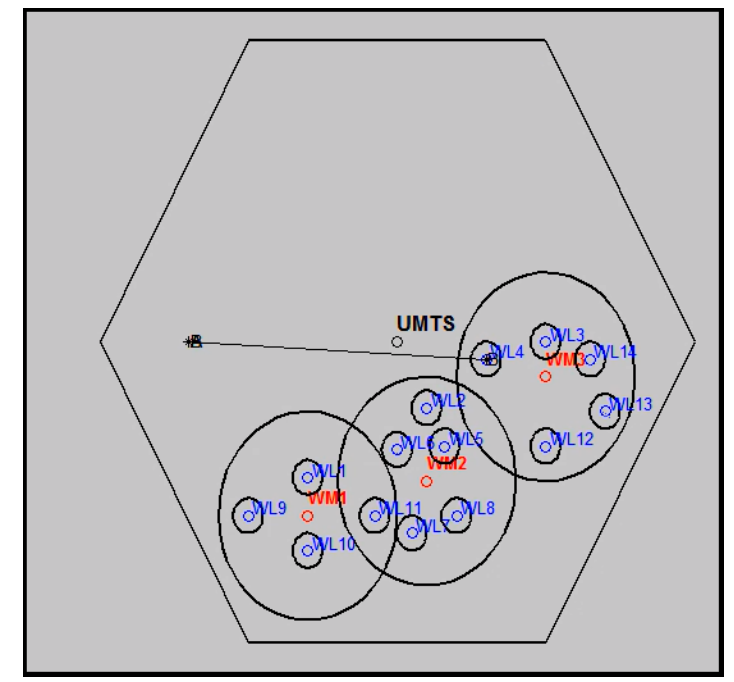

Fig.7. Mobile Node Movement from Cellular Network to WLAN

\section{RESUlTS AND ANALYSIS}

To evaluate the performance of a presented Handoff Necessity Estimation Algorithm, three metrics, i.e. predicted received signal strength (PRSS), probability of unnecessary handoff, and probability of handoff failure are considered. The simulated results are compared with an existing travelling distance algorithm proposed by Yan et al. [5], and Hysteresis based method (TDE) proposed by Lieu et al.[19].

\section{i. Predicted Received Signal Strength (PRSS)}

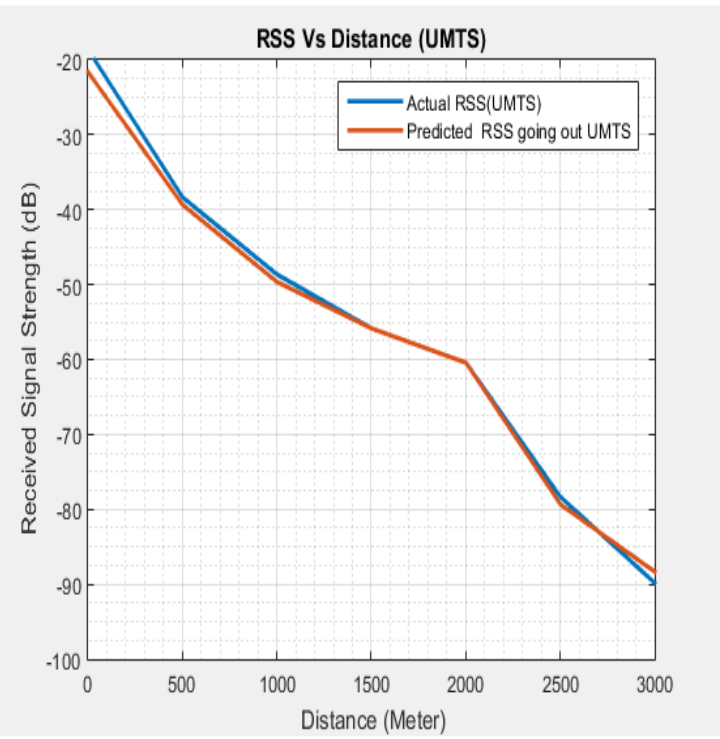

Fig.8. (a). Predicted Received Signal Strength (PRSS) of Mobile Node Moving Out from UMTS

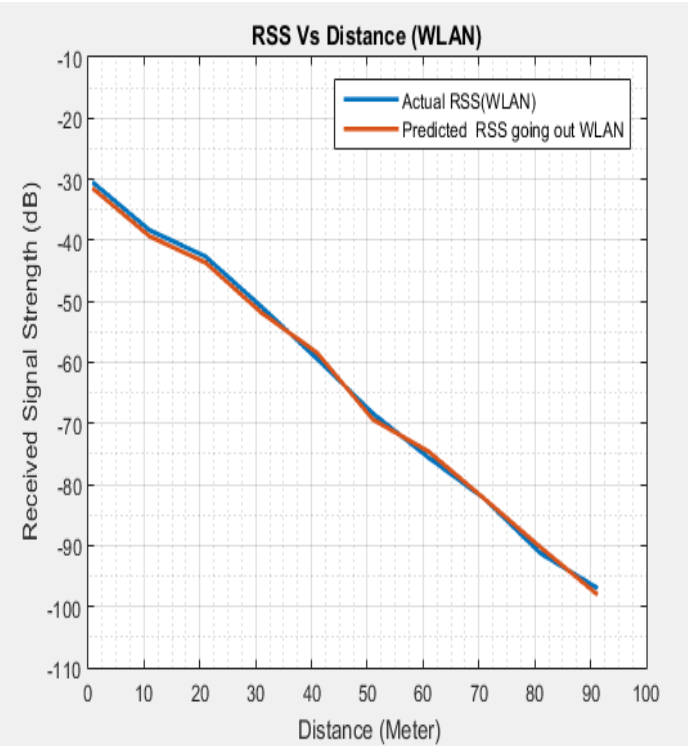

Fig.8. (b). Predicted Received Signal Strength (PRSS) Of Mobile Node Moving Out from WLAN

The RSS is directly related to the distance between the mobile node and its point of attachment. RSS is used as a primary decision criterion in most of the existing handoff decision algorithms. The accuracy of the proposed algorithm depends upon the accuracy of received signal strength prediction. PRSS of WLAN and UMTS network is shown in Fig. 8 (a) and (b). The simulated results show that the predicted received signal strength is approximately equal to the actual received signal strength. It means the proposed Levenberg Marquardt Algorithm accurately predicts the RSS. 


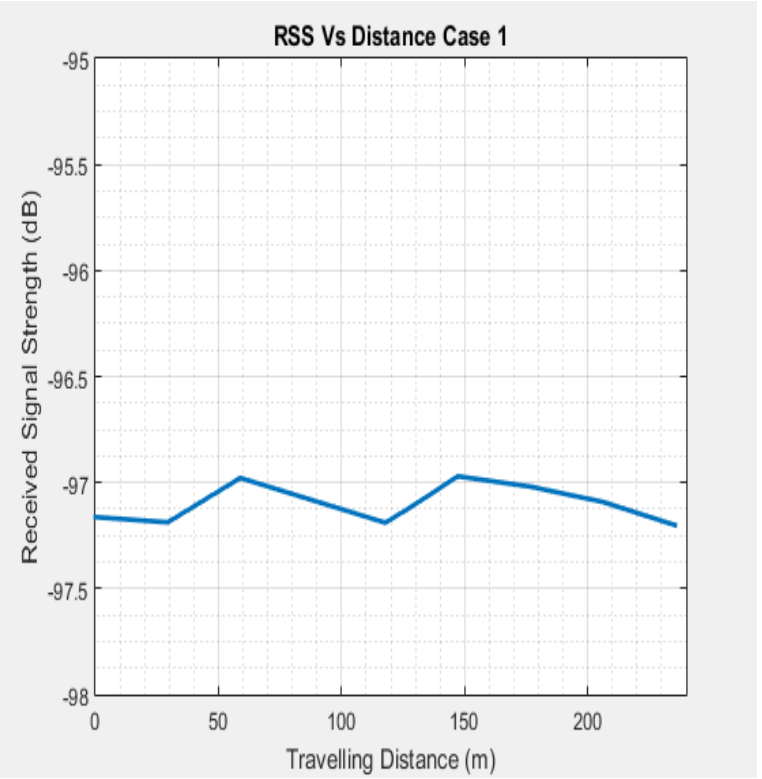

Fig.9. (a). Estimated Travelling Distance with respect to Radius (For case 1)

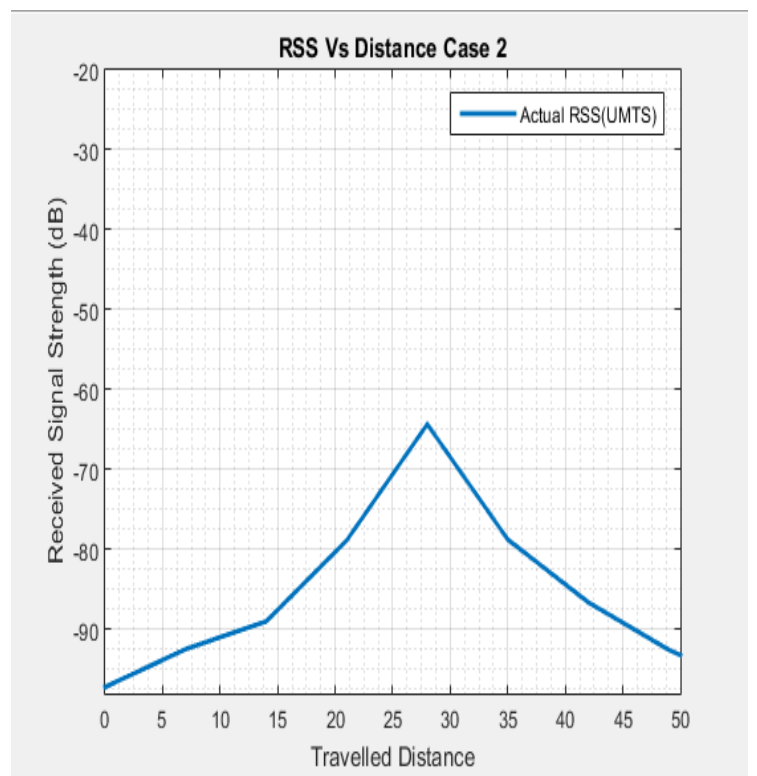

Fig.9. (b). Estimated Travelling Distance with respect to Radius (for case 2)

\section{ii. Estimated Travelling Distance with respect to Radius}

In section 2, two cases (overlapping structure and shortest predicted distance structure) are discussed. In which conventional approaches are not able to provide handoff decision algorithm effectively. Therefore, we have proposed a handoff decision depending upon travelling distance with respect to radius $\left(R_{d}\right)$. Fig. 9 (a) and (b) shows the estimated travelling distance with respect to radius for case 1 and 2 respectively. Also, table 3 and 4 shows the calculated travelling distance (d) used by conventional approach and travelling distance with respect to radius $\left(\mathrm{R}_{\mathrm{d}}\right)$ used by presented approach for case 1 and 2 respectively.

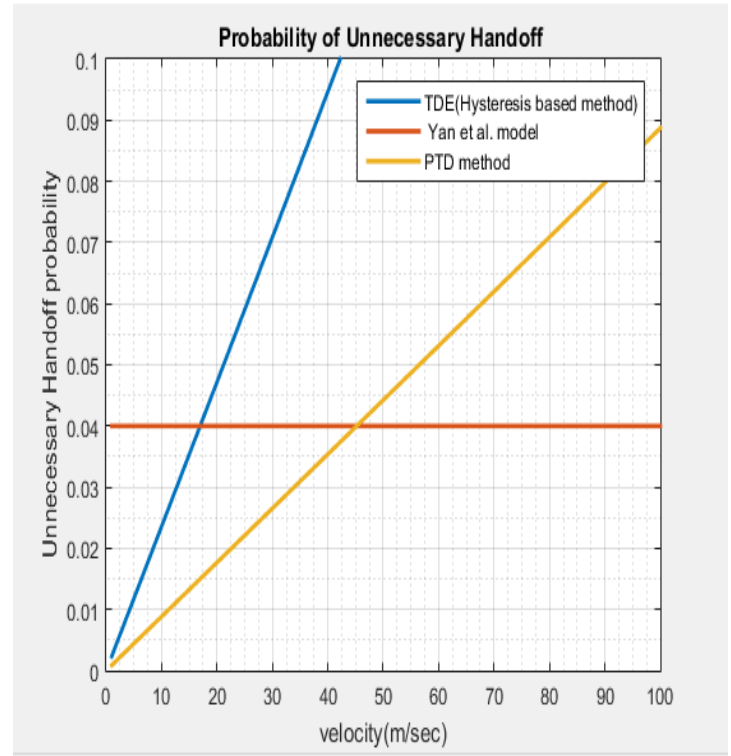

Fig.10. Probability of Unnecessary Handoffs vs. Velocity

\section{iii. Probability of Unnecessary Handoff}

Fig. 10 shows the probability of unnecessary handoff of existing travelling distance [5], Hysteresis based method (TDE) [19] and presented method (PTD). Probability of unnecessary handoffs are considerably reduced by a model proposed by Yan et al.. probability of unnecessary are constant for all velocity users. But, this value is very high for a slow velocity user. Presented algorithm (PTD) shows significant improvement in probability of handoff as compared to Hysteresis based method (TDE) because of inclusion of travelling distance with respect to radius $\left(R_{d}\right)$ instead of travelling distance (d). Table 3 shows the percentage improvement gain in probability of unnecessary handoff of presented research work as compared to the other two methods for overlapped structure as discussed in section 2 (case 1).

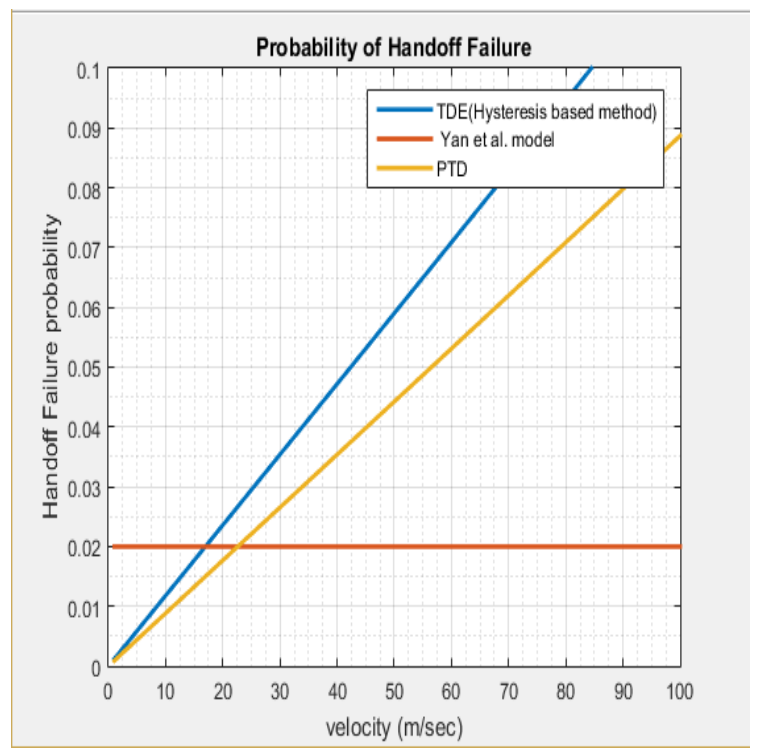

Fig.11. Handoff Failure Probability vs. Velocity 


\section{iv. Probability of Handoff Failure}

A handoff failure occurs, when the RSS of the available network goes lower than the acceptable level, before the completion of the handoff process. Or we can say that the major cause of the handoff failure arises when the target system don't have the required assets so as to complete the handoff process. Fig. 11 shows the probability of handoff failure of the existing travelling distance algorithm proposed by Yan et al.[5], Hysteresis based method (TDE) proposed by Lieu et al. [19] and presented algorithm (PTD). The model proposed by Yan gives a constant value of probability of handoff failure for all velocities, which is not good for slow velocity user. The probability of handoff failure is reduced in a presented algorithm as compared to Hysteresis based algorithm because of improved estimated travelling distance $\left(R_{d}\right)$. Table 4 shows the percentage improvement gain in probability of handoff failure for presented research work as compared to other two methods for shortest predicted distance as discussed in section 2 (case 2).

Table 3. Percentage Improvement Gain in Probability of Unnecessary Handoff (Case 1)

\begin{tabular}{|c|c|c|c|c|c|c|c|c|c|c|}
\hline \multirow{3}{*}{ S.No. } & \multirow{3}{*}{ Velocity } & \multirow{3}{*}{ RSS } & \multirow{3}{*}{$\begin{array}{c}\text { Predicted } \\
\text { travelling } \\
\text { distance (d) }\end{array}$} & \multirow{3}{*}{$\begin{array}{c}\text { Estimated } \\
\text { travelling } \\
\text { distance } \\
\text { with respect } \\
\text { to radius } \\
\left(\mathrm{R}_{\mathrm{d}}\right)\end{array}$} & \multicolumn{5}{|c|}{ Outputs } & \multirow{3}{*}{$\begin{array}{c}\% \\
\text { change }\end{array}$} \\
\hline & & & & & \multicolumn{2}{|c|}{$\begin{array}{l}\text { Handoff requirement } \\
\text { according to } \\
\text { threshold distance } \\
\text { (T_D=T_Rd=50) }\end{array}$} & \multicolumn{3}{|c|}{ Probability of unnecessary handoff } & \\
\hline & & & & & $\begin{array}{l}\text { Yan et } \\
\text { al. }\end{array}$ & $\begin{array}{l}\text { Presented } \\
\text { algo. } \\
\text { (PTD) }\end{array}$ & $\begin{array}{l}\text { Travelling } \\
\text { distance } \\
\text { algorithm } \\
\text { (Yan et } \\
\text { al.) } \\
\end{array}$ & $\begin{array}{l}\text { Hysteresis } \\
\text { based } \\
\text { algorithm } \\
\text { (TDE) }\end{array}$ & $\begin{array}{l}\text { Presented } \\
\text { algorithm } \\
\text { (PTD) }\end{array}$ & \\
\hline 1. & 10 & -97.1632 & 0 & 0.3708 & No & No & 0.04 & 0.023 & 0.007 & $53 \%$ \\
\hline 2. & 20 & -97.1876 & 29.4500 & 0.1884 & No & No & 0.04 & 0.047 & 0.015 & $51 \%$ \\
\hline 3. & 30 & -96.9785 & 58.9000 & 1.7460 & Yes & No & 0.04 & 0.070 & 0.023 & $50 \%$ \\
\hline 4. & 40 & -97.1896 & 117.8000 & 0.1732 & Yes & No & 0.04 & 0.094 & 0.032 & $49 \%$ \\
\hline 5 & 50 & -97.1144 & 88.3500 & 0.7353 & Yes & No & 0.04 & 0.1 & 0.042 & $40 \%$ \\
\hline 6. & 60 & -96.9706 & 147.2600 & 1.8049 & Yes & No & 0.04 & 0.1 & 0.05 & $33 \%$ \\
\hline 7. & 70 & -97.0194 & 176.7100 & 1.4430 & Yes & No & 0.04 & 0.1 & 0.06 & $25 \%$ \\
\hline 8. & 80 & -97.0915 & 206.1600 & 0.9062 & Yes & No & 0.04 & 0.1 & 0.07 & $17 \%$ \\
\hline 9. & 90 & -97.2014 & 235.6100 & 0.850 & Yes & No & 0.04 & 0.1 & 0.078 & $12 \%$ \\
\hline
\end{tabular}

Table 4. Percentage Improvement Gain in Probability of Handoff Failure (Case 2)

\begin{tabular}{|c|c|c|c|c|c|c|c|c|c|c|}
\hline \multirow{3}{*}{ S.No. } & \multirow{3}{*}{ Velocity } & \multirow{3}{*}{ RSS } & \multirow{3}{*}{$\begin{array}{c}\text { Predicted } \\
\text { travelling } \\
\text { distance }(\mathrm{d})\end{array}$} & \multirow{3}{*}{$\begin{array}{l}\text { Estimated } \\
\text { travelling } \\
\text { distance } \\
\text { with respect } \\
\text { to radius } \\
\quad\left(\mathrm{R}_{\mathrm{d}}\right)\end{array}$} & \multicolumn{5}{|c|}{ Outputs } & \multirow{3}{*}{$\begin{array}{c}\% \\
\text { change }\end{array}$} \\
\hline & & & & & \multicolumn{2}{|c|}{$\begin{array}{c}\text { Handoff requirement } \\
\text { acc. to threshold } \\
\text { distance } \\
\left(\mathrm{T} \_\mathrm{D}=\mathrm{T} \_\mathrm{Rd}=50\right)\end{array}$} & \multicolumn{3}{|c|}{ Probability of handoff failure } & \\
\hline & & & & & $\begin{array}{c}\text { Yan et } \\
\text { al. }\end{array}$ & $\begin{array}{l}\text { Presented } \\
\text { algo. } \\
\text { (PTD) }\end{array}$ & $\begin{array}{c}\text { Travelling } \\
\text { distance } \\
\text { algorithm } \\
\text { (Yan et } \\
\text { al.) }\end{array}$ & $\begin{array}{l}\text { Hysteresis } \\
\text { based } \\
\text { algorithm } \\
\text { (TDE) }\end{array}$ & $\begin{array}{l}\text { Presented } \\
\text { algorithm } \\
\text { (PTD) }\end{array}$ & \\
\hline 1. & 10 & -97.203 & 0 & 0.0702 & No & No & 0.02 & 0.011 & 0.008 & $15 \%$ \\
\hline 2. & 20 & -92.467 & 5.89 & 31.6848 & No & No & 0.02 & 0.023 & 0.017 & $15 \%$ \\
\hline 3. & 30 & -88.983 & 11.7 & 60.0588 & No & Yes & 0.02 & 0.035 & 0.026 & $14 \%$ \\
\hline 4. & 40 & -78.858 & 23.5 & 90.0857 & No & Yes & 0.02 & 0.047 & 0.035 & $14 \%$ \\
\hline 5 & 50 & -64.325 & 17.6 & 121.0292 & No & Yes & 0.02 & 0.059 & 0.044 & $14 \%$ \\
\hline 6. & 60 & -78.753 & 29.4 & 90.3994 & No & Yes & 0.02 & 0.070 & 0.053 & $13 \%$ \\
\hline 7. & 70 & -86.611 & 35.3 & 61.7162 & No & Yes & 0.02 & 0.082 & 0.061 & $14 \%$ \\
\hline 8. & 80 & -92.556 & 41.2 & 31.1565 & No & No & 0.02 & 0.094 & 0.070 & $14 \%$ \\
\hline 9. & 90 & -97.190 & 47.12 & 0.1685 & No & No & 0.02 & 0.1 & 0.079 & $11 \%$ \\
\hline
\end{tabular}




\section{CONCLUSIONS}

In this paper, a novel approach for estimating the necessity of making handover in WLAN is discussed. It is based on predicted received signal strength and travelling distance. Handoff Necessity Estimation Algorithm compares the Predicted Received Signal Strength (PRSS) and travelling distance with the threshold value to evaluate the necessity of making a handoff, whenever mobile node moves from cellular network to WLAN. The pre-calculation of candidate network list and PRSS helps in to maintain the connection quality and reducing the unnecessary handoff. Results are obtained for different values of travelling distance. On the basis of the simulation results, it can be observed that the proposed algorithm improves the probability of unnecessary handover and handoff failure comparing with the conventional travelling distance algorithm proposed by Yan et al., in 2008 [5], and Hysteresis based method (TDE) proposed by Liu et al. in 2008 [19].

\section{REFERENCE}

[1] Dutta, A., Das, S., Famolari, D., Ohba, Y., Taniuchi, K., Fajardo, V., \& Schulzrinne, H. (2007), 'Seamless proactive handover across heterogeneous access network', Wireless Personal Communications, vol. 43, no. 3, pp. 837-855.

[2] Zhu, K., Niyato, D., Wang, P., Hossain, E., \& In Kim, D. (2011), 'Mobility and handoff management in vehicular networks: a survey', Wireless communications and mobile computing, vol. 11, no. 4, pp. 459-476.

[3] Bhuvaneswari, A., \& Raj, E. G. D. P. (2012), 'An overview of vertical handoff decision making algorithms', International Journal of Computer Network and Information Security, vol. 4, no. 9, pp. 55.

[4] Shah, A.S. and Islam, M.S., 2014, 'A survey on cooperative communication in wireless networks', International Journal of Intelligent Systems and Applications, vol. 6, no. 7, pp. 66.

[5] Yan, X., Mani, N., \& Sekercioglu, Y. A. (2008), 'A Travelling distance prediction based method to minimize unnecessary handovers from cellular networks to WLANs', IEEE communications letters, vol. 12, no. 1, pp. 14-16.

[6] Kunarak, S. and Suleesathira, R., 2013, 'Algorithmic vertical handoff decision and merit network selection across heterogeneous wireless networks', WSEAS Transactions on Communications, vol. 12, no. 1, pp.1-13.

[7] Bo, S., Lin, L. and Feng, D., 2014, June. 'The multiattribute vertical handoff algorithm based on node mobility', In fifth International Conference on Software Engineering and Service Science (ICSESS), IEEE.

[8] Gao, W. and Zhang, W., 2015, October. 'Conserving mobile terminal's energy using a novel network selection mechanism in integrated UMTS/WLANs', In International Conference and Workshop on Computing and Communication (IEMCON), pp. 1-5, IEEE.

[9] Ostlin, E., Zepernick, H.J. and Suzuki, H., 2010, 'Macrocell path-loss prediction using artificial neural networks', IEEE Transactions on Vehicular Technology, vol. 59, no. 6, pp.2735-2747.

[10] Popescu, I., Nikitopoulos, D., Constantinou, P. and Nafornita, I., September. 2006, 'Comparison of ANN Based Models for Path Loss Prediction in Indoor Environment', In IEEE 64th Conference on Vehicular Technology (VTC-2006 Fall), pp. 1-5, IEEE.

[11] Sapna, S., Tamilarasi, A. and Kumar, M.P., 2012, 'Backpropagation learning algorithm based on Levenberg Marquardt Algorithm', Comp Sci Inform Technol (CS and IT), 2, pp.393-398.

[12] Chang, B.J. and Chen, J.F., 2008, 'Cross-layer-based adaptive vertical handoff with predictive RSS in heterogeneous wireless networks', IEEE Transactions on vehicular technology, vol. 57, no. 6, pp.3679-3692.

[13] Majlesi, A. and Khalaj, B.H., September. 2002, 'An adaptive fuzzy logic based handoff algorithm for interworking between WLANs and mobile networks', In the 13th IEEE International Symposium on Personal, Indoor and Mobile Radio Communications, vol. 5, pp. 2446-2451, IEEE.

[14] Madaan, J. and Kashyap, I., 2016, 'Vertical Handoff Decision Algorithm Based on PRSS and Dwell Time', International Journal of Computer Network and Information Security (IJCNIS), vol. 8, no. 7, pp. 31.

[15] Ho, M.J., Rawles, M.S., Vrijkorte, M. and Fei, L., March. 2002, 'RF challenges for 2.4 and $5 \mathrm{GHz}$ WLAN deployment and design', In Wireless Communications and Networking Conference ( WCNC2002), Vol. 2, pp. 783-788, IEEE.

[16] Jeon, S. and Lee, S., 2007. A relay-assisted handover technique with network coding over multihop cellular netorks. IEEE Communications Letters, vol. 11, no. 3.

[17] He, D., Chi, C., Chan, S., Chen, C., Bu, J. and Yin, M., 2011, 'A simple and robust vertical handoff algorithm for heterogeneous wireless mobile networks', Wireless Personal Communications, vol. 59, no. 2, pp.361-373.

[18] Mohanty, S. and Akyildiz, I.F., 2006, 'A cross-layer (layer $2+3$ ) handoff management protocol for nextgeneration wireless systems', IEEE Transactions on Mobile Computing, vol. 5, no. 10, pp.1347-1360.

[19] Liu, M., Li, Z., Guo, X. and Dutkiewicz, E., 2008, 'Performance analysis and optimization of handoff algorithms in heterogeneous wireless networks', IEEE Transactions on Mobile Computing, vol. 7, no. 7, pp.846857.

\section{Authors' Profiles}

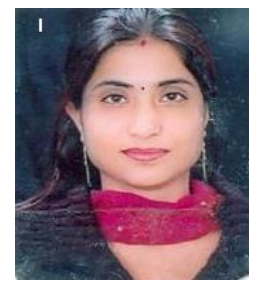

Jyoti Madaan was born in 1983 at Faridabad, Haryana, India. She received her Master's Degree in Electronics \& Communication Engineering in the years 2009. She is working as Assistant Professor, Department of Electronics \& Communication Engineering, at Manav Rachna International University, Faridabad, India, since 2010. Currently, she is doing her research in the area of Wireless Networks under the guidance of Dr. Indu Kashyap. 


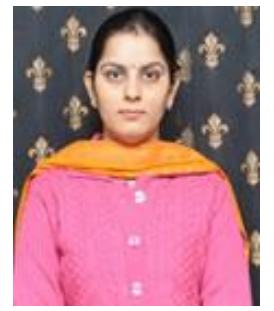

Dr. Indu Kashyap received her Doctorate in Computer Science in the year 2012. She has around Eight years of Academic experience in the field of Computer Science. Currently She is working as Associate Professor in the Department of Computer Science and Engineering at Manav Rachna International University, Faridabad, India. Her research interest includes Wireless networking, Mobile computing, Computer Communication and Networks. She has published several papers in National, International Journals and Conferences related to Computer Science and has been a reviewer member in Manav Rachna International University.

How to cite this paper: Jyoti Madaan, Indu Kashyap, "A Novel Handoff Necessity Estimation Approach Based on Travelling Distance", International Journal of Intelligent Systems and Applications(IJISA), Vol.10, No.1, pp.46-57, 2018. DOI: 10.5815/ijisa.2018.01.06 